\title{
Effect of Through-plane Polytetrafluoroethylene Distribution in Gas Diffusion Layers on Performance of Proton Exchange Membrane Fuel Cells
}

Hiroshi Ito ${ }^{a^{*}}$, Takuya Iwamura ${ }^{a}$, Satoshi Someya ${ }^{a}$, Tetsuo Munakata ${ }^{a}$, Akihiro Nakano ${ }^{\text {a }}$, Yun Heo ${ }^{\text {b }}$, Masayoshi Ishida ${ }^{b}$, Hironori Nakajima ${ }^{c}$, Tatsumi Kitahara ${ }^{c}$

a: Research Institute for Energy Conservation, National Institute of Advanced Industrial Science and Technology (AIST), 1-2-1 Namiki, Tsukuba 305-8564, Japan

b: Department of Engineering Mechanics and Energy, University of Tsukuba, 1-1-1 Tennoudai, Tsukuba 305-8573, Japan

c: Department of Mechanical Engineering, Kyushu University, 744 Motooka, Nishi-ku, Fukuoka 819-0395, Japan

*Corresponding author, E-mail: ito.h@aist.go.jp

\footnotetext{
Abstract

This experimental study identifies the effect of through-plane polytetrafluoroethylene (PTFE) distribution in gas diffusion backing (GDB) on the performance of proton exchange membrane fuel cells (PEMFC). PTFE-drying under vacuum pressure created a relatively uniform PTFE distribution in GDB compared to drying under atmospheric pressure. Carbon paper samples with different PTFE distributions due to the difference in drying conditions were prepared and used for the cathode gas diffusion layer (GDL) of PEMFCs. Also investigated is the effect of MPL application on the performance for those samples. The current density (i) - voltage (V) characteristics of these PEMFCs measured under high relative humidity conditions clearly showed that, with or without
} 
MPL, the cell using the GDL with PTFE dried under vacuum condition showed better performance than that dried under atmospheric condition. It is suggested that this improved performance is caused by the efficient transport of liquid water through the GDB due to the uniform distribution of PTFE.

Key word: proton exchange membrane fuel cell; gas diffusion layer; PTFE distribution; water breakthrough pressure; contact angle 


\section{Introduction}

The critical component of a proton exchange membrane fuel cell (PEMFC) is the membrane-electrode assembly (MEA), which typically consists of a catalyst-coated membrane $(\mathrm{CCM})$ and a gas diffusion layer (GDL) on both sides. In the CCM, a catalyst layer (CL) is coated and bonded on a proton exchange membrane (PEM) on both sides. The GDL is a critical component of a PEMFC, where its basic functions are effective transport of reactant gas to CL, drainage of liquid water into channels or keeping the PEM wet, high electric conduction between CL and the bipolar plates, and mechanical support of the CCM. In particular at the cathode, because water is produced by the reaction at the CL, the GDL functions related to water management, that is, attaining an appropriate balance of retention/exclusion of water, are essential for stable operation under a wide range of current density [1,2].

Relative humidity $(\mathrm{RH})$ of the gases in the channel is an important parameter in evaluating the water management in a PEMFC. Recent commercialized fuel cell vehicles (FCV) [3] do not contain any individual humidifier due to cost reduction, conservation of parasitic energy, and simplifying and downsizing of the power system, when the inlet RH of cathode gas (air) might be relatively low. However, based on experimental results using fuel cells at a commercially available scale $\left(50 \mathrm{~cm}^{2}\right)$, Mench et al. [4] and Yang et al. [5] revealed that the RH of cathode gas increases along the channel and sometimes reaches saturation near the exit even when the inlet RH is low (e.g., $20 \%$ ), because product water is entrained in the flow channel. In particular, during the start-up period of FCVs, when the cell temperature is low and flooding tends to occur easily even at low current density, flooding should be carefully avoided at the cathode. Thus, the cathode GDL must retain its water management functions under a wide range of humidity conditions.

A basal substrate of GDL, called a gas diffusion backing (GDB), is made of materials that have high porosity and electric conductivity, such as woven carbon cloth, non-woven carbon paper, 
or non-woven carbon felt [6]. A GDL is generally composed of GDB coated with a hydrophobic microporous layer (MPL), which is usually a mixture of fine carbon particles and a hydrophobic agent. To improve their gas and water transport, GDBs are commonly treated with a hydrophobic agent such as polytetrafluoroethylene (PTFE) to increase the hydrophobicity.

The effect of PTFE content in carbon-paper GDLs without MPL (i.e., GDB) on the PEMFC performance has been experimentally examined [7-10]. In general, the addition of PTFE to the GDB reinforces the hydrophobicity of pores in the GDB, which can then improve the cell performance. However, excessive PTFE loading can reduce the pore size, making expulsion of liquid water from the pores more difficult. Those previous studies therefore concluded that there is an optimal PTFE content. Although the loading amount of PTFE was discussed in those studies [7-10], the PTFE distribution throughout the GDB in the through-plane direction was not examined.

Several recent works [6,11-15] have investigated the PTFE through-plane distribution in GDBs. Mathias et al. [6] reported that PTFE dispersion drying time can affect its distribution. Based on their measurements of PTFE through-plane distribution in relation to PTFE dispersion drying times, they reported that relatively slower drying times yielded higher concentrations in the interior of the GDB, whereas relatively faster drying times yielded higher concentrations near the surface. Quick et al. [11] prepared several carbon felt samples of PTFE treated with different drying times (the same drying times as those used by Mathias et al. [6]), and examined the effect of PTFE through-plane distribution on the water transport rate via GDB using an ex-situ measurement apparatus. Their results revealed that the GDB with PTFE that was dried slowly shows higher water transport rate than that with PTFE dried rapidly. Although their measurements were comprehensive, they did not present any observation of the PTFE distribution [11]. Fishman and Bazylak [12] measured the porosity through-plane distribution of carbon-paper GDB using microscale computed tomography $(\mu \mathrm{CT})$ imaging. Based on comparison of porosity distribution between GDB samples 
with and without PTFE treatment, PTFE preferentially accumulated at the local area in the through-plane direction near the surface [12]. Rofaiel and Bazylak et al. [13] measured the heterogeneous through-plane PTFE distribution for different types of GDB (paper, felt, and cloth) using scanning electron microscopy (SEM)-based energy dispersive X-ray spectroscopy (EDS) imaging. They reported that the morphological features of untreated GDB significantly affect the PTFE distribution. Based on two-phase model calculation results, Kang et al. [14] correlated the profile of liquid water saturation with that of PTFE content throughout the GDB, and reported that the centrally located saturation peaks in the through-plane profile can be attributed to relatively fewer PTFE-coated pores in the inner GDB region. Our previous study [15] investigated the relation between the pressure condition during drying period of PTFE and the resulting through-plane PTFE distribution in carbon paper using SEM-EDS analysis. Our results revealed that PTFE-drying under vacuum pressure created a relatively uniform PTFE distribution, whereas PTFE-drying under atmospheric pressure created highly heterogeneous PTFE distributions in the through-plane direction.

It is well known that the application of MPL on GDB improves mass transport through the GDL [16-18]. Several hypotheses about the role of an MPL have been suggested. For example, Weber and Newman [19] hypothesized that a capillary barrier acts as a valve to repel water from the oxygen-electrode GDL and to accelerate back diffusion of water from the cathode to the anode through the membrane. Wang et al. [20] pointed out that in hydrophobic meso-pores (pore diameter: 0.05 to $7 \mu \mathrm{m}$ ), liquid water does not easily penetrate into the pore because it needs to overcome the surface energy. Consequently, hydrophobic meso-pores are dry (i.e., "open"), and thus can act as a gas transport path. Gostick et al. [21] indicated that the MPL contributes to lower water saturation in GDL when the water breaks through the GDL. In addition, previous studies have experimentally examined the effect of MPL properties on the cell performance, focusing on the type of carbon 
powder [20,22-24], content of carbon powder [25], PTFE content [26], and fabricating process [27]. Ramasamy et al. [28] comprehensively studied the effects of interaction between GDB and MPL on the cell performance using different types of GDB such as carbon cloth (Gore) and carbon paper (Toray and Sigracet). Their results indicated a strong and complex interaction between GDB and MPL, although no distinct trend was observed in the nature of this interaction with respect to the bulk properties of the tested GDB [28]. Lee et al. [29] visualized liquid water distribution in GDL with and without MPL using synchrotron X-ray radiography, and their observations indicated that the presence of the MPL significantly reduced the water content at the interfacial region between CL and GDL.

In order to understand the dynamic behavior of liquid water through the GDL, different types of measurements of water injection into GDL samples have been attempted by several researchers as an ex-situ approach $[18,21,30-35]$. In those studies, the measurement apparatus was specially designed depending on each objective. Benziger et al. [30] measured hydrostatic water pressure at breakthrough and water flow rate through various types of GDL. Gostick et al. [31] measured the relationship between capillary pressure and liquid water saturation in GDLs, and detected the water saturation at breakthrough using GDLs with and without MPL [21]; their data demonstrated that liquid water saturation in a GDL at water breakthrough is drastically reduced due to the presence of MPL as noted above. Lu et al. [32] measured the water pressure and liquid water saturation at the breakthrough condition using GDLs with and without MPL, and also visualized water breakthrough from above of the sample surface. It has been reported by $\mathrm{Lu}$ et al. [32] that water saturation of GDLs with MPL is definitely lower than that of GDLs without MPL, and a dynamic change in water breakthrough locations has been observed in GDLs without MPL but not in GDLs with MPL. Santamaria et al. [33] investigated the breakthrough pressure, droplet adhesion force, and detachment velocity in Toray carbon papers. Mortazavi and Tajiri [34] also measured the 
breakthrough pressure at Toray papers with different amounts of PTFE loading. Kitahara et al. [18, 35] evaluated the contact angle of GDLs with MPL by combining capillary flow porometry (CFP) $[36,37]$ and water injection, and revealed that the contact angle obtained by this combined method clearly increased with increasing PTFE content in MPL, whereas the contact angle observed by the sessile droplet method was almost identical for different amounts of PTFE [18].

In this study, aiming to identify the effect of the through-plane PTFE distribution in GDB on the cell performance, carbon paper samples treated with PTFE under different drying conditions were prepared and used for the cathode GDL of PEMFCs. These carbon papers coated by an MPL were also prepared and tested with PEMFC. The current density (i) - voltage $(V)$ characteristics were measured at high RH conditions using a small-scale fuel cell. The through-plane PTFE distributions in GDL were evaluated with SEM-EDS analysis. In addition, the GDL properties related to water transport were examined using an ex-situ measurement of the GDL samples.

\section{Experiments}

\subsection{Sample preparation}

As a commercial product available for carbon-paper GDLs of PEMFCs, Toray-paper (TGP-H-090) was selected and treated as follows. A total of five samples were prepared for the cathode GDL, and the cell notation for these samples is represented here by the feature of the cathode GDL as summarized in Table 1: (1) bare carbon-paper not treated with PTFE (sample CT-BA), (2) carbon-paper treated with PTFE under air-drying conditions (CT-AD), (3) carbon-paper treated with PTFE under vacuum-drying conditions (CT-VD), (4) MPL applied on carbon-paper treated with PTFE under air-drying conditions (CT-AD-M), and (5) MPL applied on carbon-paper treated with PTFE under vacuum-drying conditions (CT-VD-M). 
The procedure of PTFE treatment for the Toray-paper substrate $(50 \times 50 \mathrm{~mm})$ was identical with that in a previous study [15]. Each sample was dipped in a PTFE dispersion (D-210C, Daikin) for about 2 minutes, and then placed on a needle-point holder. The holder with the sample was immediately placed in a drying oven (VT220, Etak) at room temperature, and the oven was then heated immediately after the door was closed. The oven was heated to $100^{\circ} \mathrm{C}$ in about $30 \mathrm{~min}$, then kept at that temperature for 1 hour, after which the heating was turned off. The sample was left in the oven for over 10 hours until the oven reached room temperature. For the air-drying condition (sample CT-AD), the oven was open to the air through a pipe, although the door was closed. For the vacuum-drying condition (sample CT-VD), the air in the oven was evacuated just after the door was closed, and the pressure was kept at vacuum until the door was opened after the oven reached room temperature. After either drying process, both CT-AD and CT-VD samples were transferred to another oven and sintered at $360^{\circ} \mathrm{C}$ for 1 hour under vacuum conditions.

In the preparation of CT-AD-M and CT-VD-M, the above PTFE treatment was followed by an in-house application of MPL as follows. First, a mixed solution was prepared by containing acetylene black (HS-100, Denka), PTFE dispersion (D-210C, Daikin), deionized water, and surface active agent (Triton X, Dow Chemical). Next, the solution was stirred thoroughly using a homogenizer and changed to a slurry with higher viscosity. Then, the slurry was spread on the substrate using a coating machine with a doctor blade. Finally, the MPL coated sample was dried under atmospheric condition (air drying) at $100^{\circ} \mathrm{C}$ for 1 hour and sintered at $360^{\circ} \mathrm{C}$ for 1 hour under vacuum conditions. In this preparation, the composition of mixed solution and the application process (stirring, coating, drying, and sintering) was the same for both CT-AD-M and CT-VD-M samples, and the PTFE content in the MPL was set at $27 \mathrm{wt} . \%$.

\subsection{Scanning electron microscopy (SEM) based energy dispersive X-ray spectroscopy (EDS)}




\section{analysis}

The methodology of SEM imaging and EDS analysis applied here was identical with that of Rofaiel et al. [13] and our previous study [15]. For EDS analysis, a fragment of each sample was obtained from the used substrate for the cell tests (described in the following section). Each fragment sample was first frozen using liquid nitrogen and then immediately cut with a knife to reveal a sharp cross-section. The SEM imaging (JEOL JSM-7400F SEM) and EDS maps of the cross-sectional images of each carbon-paper GDL were used to quantify the fluorine (F) content of the GDL, because $\mathrm{F}$ is a suitable element for determining the presence of PTFE throughout the GDL due to its high concentration in PTFE and its absence in carbon-paper. In our previous study [15], the SEM magnification was $100 \times$ and the spatial resolution for the EDS map was about $5 \mu \mathrm{m}$. In the present analysis, in order to obtain higher spatial resolution for the EDS map, the SEM magnification was increased to $200 \times$ and the spatial resolution was about $2.5 \mu \mathrm{m}$. For each sample, three EDS maps were taken from adjacent regions so that a continuous image was captured. The total size of the continuous EDS image was about 750 pixels in the in-plane direction, whereas in the through-plane direction, it varied between 130 and 150 pixels depending on the sample thickness.

The F map images were treated and analyzed using an image translation program (Image J). The grey-scale value of each pixel along the in-plane direction of the image (horizontal axis in the EDS map) was summed to obtain a relative PTFE value along the thickness of the GDL. Finally, the relative F (i.e., relative PTFE) values were normalized across the through-plane direction (z).

\subsection{Capillary flow porometry and water injection}

A series of ex situ measurements were done to evaluate the GDL properties, that is, pore diameter $d_{\mathrm{p}}$ and contact angle $\theta$. The sample holder for these ex-situ measurements was built in-house and had a similar structure to the holder used in previous studies [35,36]. A disk sample of 
GDL (14 mm in diameter) was placed between two plates and sealed by an "O" ring. The fluid passed through the sample in the through-plane direction, during which the flow rate $Q$ and the differential pressure between inlet and exit (ambient) $\Delta P$ were monitored.

In one series of measurements, first, $d_{\mathrm{p}}$ was measured using capillary flow porometry (CFP) as follows. A sample disk was soaked in a wetting liquid which has sufficiently low surface tension (Galwick, $0.0157 \mathrm{Nm}^{-1}$ at room temperature) and spontaneously seeps into the pores. The prewetted substrate was placed in the holder and dry air was then introduced. Removal of the wetting liquid from the pores was not spontaneous, however, the equilibrium relationship between the surface tension of the liquid $\gamma$ and $\Delta P$ was used to calculate $d_{\mathrm{p}}$ :

$$
d_{\mathrm{p}}=\frac{4 B \gamma \cos \theta}{\Delta P}
$$

where $B$ is the capillary constant; $\gamma$ is the surface tension, $\theta$ is the contact angle; and $\Delta P$ is applied gas pressure. The capillary constant is a tortuosity factor set at 0.715 in the present measurement, the same value stated by the American Society for Testing Material Committee (ASTM) [37]. When the wetting liquid has very low $\gamma\left(=0.0157 \mathrm{Nm}^{-1}\right)$ and $\theta$, then $\cos \theta$ can be assumed to be 1 regardless of $d_{\mathrm{p}}$. There would be no gas flow through the substrate containing liquid-filled pores, and the gas begins to flow when $\Delta P$ is increased to a value sufficient to empty the largest pore. This gas breakthrough point is called the bubble point. Further increase in $\Delta P$ would empty the smaller pores and increase $Q$, and the wetting liquid in the substrate entirely removed by the air flow. Consequently, the wet curve to show the relation between $\Delta P$ and $Q$ can be obtained for the range from the bubble point to fully dry condition of the sample. Next, dry air was introduced to this dried sample in the same holder, and the dry curve was measured for the same pressure range as the wet curve. The half-dry curve was calculated from the dry curve and was half of the flow rate through the dry sample at any given $\Delta P$. The maximum $d_{\mathrm{p}}$ obtained from the $\Delta P$ of the bubble point and Eq. (1) is called the bubble point diameter (BPD), and $\Delta P$ at the intersection of the half-dry and wet 
curve is the mean pore diameter (MPD). In general, CFP is defined as the measurement method for BPD and MPD [37]. In this series of ex-situ measurements, after the wetting liquid was removed completely as described above, CFP was followed by water injection, that is, liquid water was introduced into the same sample kept in the holder. The inlet pressure of water was increased and the liquid water could pass through the GDL pores at that given pressure. This water breakthrough pressure $\left(\Delta P_{\mathrm{WB}}\right)$ could be detected by a spiky change in $\Delta P$ [34]. Both gas and liquid water preferentially pass through the largest pores in GDL. It can be assumed that the route in GDL is common for both the gas (bubble point) and water (breakthrough) and that the diameter representing the route is defined by BPD obtained by CFP. Thus, Eq. (1) can also describe the equilibrium relationship between surface tension of liquid water and applied water pressure. When the breakthrough pressure could be obtained by water injection method, contact angle $(\cos \theta)$ corresponding to the largest pores in GDL can be easily calculated by Eq. (1) substituting BPD and surface tension of liquid water $\left(=0.07275 \mathrm{Nm}^{-1}\right)$ for $d_{\mathrm{p}}$ and $\gamma$, respectively. In these measurements, the top side of sample (in Figs. 3 and 4) was oriented to the bottom side of the sample holder, which means the fluids (gas and water) were always injected into the top side of the sample during the PTFE drying.

This water injection technique was first developed by Kitahara et al. [18], and applied for evaluation of $\theta$ for GDLs with MPLs that contained different amounts of hydrophobic agent (PTFE). That study presented a clear relation between $\theta$ and PTFE content in MPL, that is, MPL containing higher PTFE content showed higher $\theta$.

\subsection{Measurements of porosity and in-plane permeability}

Initial bulk porosity of the samples was also measured by the same technique used in our previous study [15], that is, weighing the sample before and after immersion in a wetting liquid, 
decane, which has low $\gamma\left(0.0234 \mathrm{~N} \mathrm{~m}^{-1}\right)$ and thus has the ability to fill all pores. Although the porosity of the MPL must be significantly lower than that of the GDB, it was impossible to measure the MPL porosity independently, because the MPL was partially immersed in the GDB. Our present data of porosity thus represents the total bulk porosity of the GDL substrate, even when the MPL was applied.

In-plane permeability of the GDL samples was measured with the same set-up and procedure used in our previous study [15]. The sample thickness was regulated by the spacer thickness during the in-plane permeability measurement and was fixed at $200 \mu \mathrm{m}$, which was identical with the thickness of the gasket in the cell set-up described below (Sec. 2.5).

\subsection{Cell performance test}

In this study, aiming to investigate the GDL functions under severe wet conditions, the performance of the fuel cells was examined at high RH conditions $(80-152 \%)$. Furthermore, to eliminate the change in gas composition, pressure, and humidity along the channel, a small-scale single cell with $1 \mathrm{~cm}^{2}$ active area (square) was used for the experiments. Five different samples (Table 1) were prepared as the cathode GDL in each cell test. A CCM was placed between the carbon-paper GDLs and bipolar plates. Both bipolar plates were made of carbon material and had a triple-parallel serpentine flow field. A small piece of the square sample $(10 \times 10 \mathrm{~mm})$ was punched out from the treated substrate $(50 \times 50 \mathrm{~mm})$ mentioned above (Sec. 2.1$)$ and used for the cathode GDL, and untreated carbon paper (i.e., CT-BA) was commonly used as the anode GDL. A 200- $\mu \mathrm{m}$-thick PTFE sheet was used for the gasket. Although the cell was assembled under a compression of about $3 \mathrm{MPa}$, it was confirmed that the thickness of the gasket did not change under this compression. This means that the GDL in the cell was compressed and that its thickness was reduced to $60-70 \%$ from the original depending on its initial thickness (Table 1). 
Fuel cell operation was controlled by using a station specifically equipped (PEMTEST8900, Toyo), namely, with a temperature controller for the cell and a gas supply unit with mass flow meters and humidifiers. The cell temperature was kept constant by electric heaters on both cover-plates controlled by the station. Pure hydrogen and air $\left(\mathrm{O}_{2}\right.$ content: $\left.21 \%\right)$ were introduced to the anode and cathode of the cell, respectively, and the back pressure of both sides was set at 150 $\mathrm{kPa}(\mathrm{abs})$. The effect of concentration distribution along the channel was minimized by keeping the gas flow rate of the introduced gases high enough $(500 \mathrm{~mL} / \mathrm{min}$ for both gases) to maintain stoichiometries of $\mathrm{H}_{2}$ and $\mathrm{O}_{2}$ at about 350 and 14 at $2 \mathrm{~A} / \mathrm{cm}^{2}$, respectively. The $\mathrm{RH}$ in the cell was precisely controlled by carefully regulating the dew-point of the introduced gases. The dew-point was kept at the same temperature as the humidifier (bubbling tank) by heating the pipeline (wrapped in a ribbon heater from the station to the cell). The dew point at the exit of the pipeline (i.e., inlet of the cell) was calibrated with a mirror-type dew-point meter (ILD, Toyo) prior to cell tests.

The $i-V$ characteristics were measured for the cell using the galvanostatic operation of the electrochemical interface (1287, Solartron) at a sweep rate for $i$ of $5 \mathrm{~mA} / \mathrm{sec}$ from the open circuit voltage (OCV) to $V=0.050 \mathrm{~V}$. The maximum $i$ of this instrument was $2 \mathrm{~A}$. The cell impedance was also measured at each operating condition using a frequency response analyzer (FRA) (1255, Solartron) connected with the electrochemical interface, for a bias current from 0 to the limiting $i$ of the measured $i-V$ characteristics at a fixed frequency of $10 \mathrm{kHz}$.

\section{Results and discussion}

In our experiments, the prepared substrate of GDL $(50 \times 50 \mathrm{~mm})$ was divided into several samples for different evaluations; a) for GDL of the cell, b) for CFP analysis (including water injection), c) for in-plane permeability measurements, and d) for porosity measurements. The sample 
for SEM/EDS analysis was actually the GDL removed from the cell after the cell test and then dried and cut. The SEM analysis was not affected by compression of the GDL in the cell set-up. In addition, because the duration of the cell operation was limited (less than 10 hours), detachment of PTFE from the GDL was assumed negligible.

\subsection{SEM/EDS analysis}

Prior to the analysis on the PTFE-treated carbon papers, EDS maps of fluorine (F) were observed for the untreated sample (CT-BA), confirming that no signal of $\mathrm{F}$ was detected. Figure 2 shows the cross-sectional SEM images and EDS maps for F of four different samples (CT-AD, CT-VD, CT-AD-M, and CT-VD-M). The upper portion of each image in Fig. 2 corresponds to the top of the sample during the PTFE-drying treatment; air-drying for CT-AD and vacuum-drying for CT-VD (see 2.1). Comparison of the EDS maps for F for CT-AD (Fig. 2(a)) and CT-VD (Fig. 2(b)) samples reveals a significant difference in PTFE distribution. (Note that the total amount of PTFE loading was nearly the same for each of the two samples, CT-AD and CT-VD, as listed in Table 1.) For CT-AD, PTFE was heterogeneously localized near the upper surface, whereas for CT-VD, PTFE was distributed more homogeneously throughout the bulk. Although the PTFE-loading amount in carbon paper (Toray 090) in our present study (ca. 5wt.\%) was significantly lower than that of our previous study (ca. 14 wt.\%) [15], the difference in PTFE distribution between CT-AD and CT-VD was in good agreement with the previous study. This difference in PTFE distribution between CT-AD and CT-VD can be explained as follows; liquid water in the PTFE solution was mainly evaporated from both the top and bottom surfaces during the drying process. As for air-drying, the PTFE solution distributed around the central area was transported to the surfaces by capillary force due to the decrease in water near the surface, and finally the PTFE dried and agglomerated near the surface. In particular, in this case of CT-AD, because evaporation occurred mainly from the top 
rather than the bottom, PTFE was heterogeneously present near the top surface. In the case of vacuum drying, because the evaporation rate of water was significantly high, the effect of capillary pressure on the agglomeration was limited, and thus PTFE was distributed more evenly throughout the bulk.

Figure 2 also shows the cross-sectional SEM images and EDS maps of CT-AD-M (Fig. 2(c)) and CT-VD-M (Fig. 2(d)) samples. For these samples, the MPL was applied to the top side, which corresponds to the top side during the drying process of PTFE the same as in Figs. 2 (a) and 2 (b). The SEM images reveal that the sublayer consisted of densely-packed carbon powder that covered the GDB. The SEM image also reveals that the morphological feature of MPL was similar in both the CT-AD-M and CT-VD-M samples as expected, that is, the thickness of MPL was 40-60 $\mu \mathrm{m}$, whereas the MPL was partially sunk into the bulk of GDB $(5-10 \mu \mathrm{m})$. For both samples, the total thickness was $320 \mu \mathrm{m}$ (Table 1). Because the MPL contained a higher PTFE amount per weight (27 wt.\%) than the GDB (4.9-6.5 wt.\%), the PTFE band could be observed along the MPL in the EDS maps of CT-AD-M and CT-VD-M. In the case of CT-AD-M, the PTFE was near the bottom surface, which is different from that in CT-AD, where the PTFE was detected only in near the top surface. The difference might be caused by slight difference in treatment condition or procedure (i.e., room temperature or time-gap between sample setting and heating-up for drying). However, same as the CT-AD, the CT-AD-M had almost no PTFE around the central region in the through-plan direction. In the case of CT-VD-M, the PTFE distribution was homogeneous and similar to that in CT-VD except for the PTFE band of MPL.

Figure 3 shows the through-plane distributions of the PTFE fraction $\left(f_{\mathrm{PTFE}}\right)$ calculated from the EDS maps for samples CT-AD, CT-VD, CT-AD-M, and CT-VD-M. Because the summed total value of $f_{\mathrm{PTFE}}$ was normalized to $100 \%$ for these four samples, these distribution plots do not provide a quantitative analysis of the actual PTFE content in the through-plane direction. For the graphs in 
Fig. 3, the left side $(z=0)$ corresponds to the top of the sample during the drying process of PTFE. In the cell set-up, the GDL/CL interface was oriented along the top side $(z=0)$, and the GDL/flow channel interface was oriented along the bottom side $(z=1)$. Results clearly show that in the cases of CT-AD and CT-AD-M, the PTFE content was very low at the central region in the through-direction, and contrary to this, in the cases of CT-VD and CT-VD-M, the PTFE distribution was relatively uniform throughout the bulk of GDL (GDB+MPL). In comparison of Fig. 3 (c) and Fig. 3 (d), $f_{\mathrm{PTFE}}$ in the MPL area of CT-VD-M was lower than that of CT-AD-M. It was deduced that the flatness of cut surface of CT-VD-M was not enough in MPL region, and the detected signals of F was low with EDS.

\subsection{Pore diameter, water breakthrough pressure, and contact angle}

Two or three pieces of each GDL sample were obtained from one base substrate $(50 \times 50$ $\mathrm{mm}$ ) and applied for the CFP and water breakthrough measurements. The average values of BPD and MPD are listed in Table 1, although it was impossible to measure the MPD for the MPL-applied samples (CT-AD-M and CT-VD-M) due to heterogeneous porosity distributions as described above. In CT-AD, both BPD and MPD were almost the same as those in CT-BA even though PTFE was loaded, whereas in CT-VD, they both decreased significantly compared with those in CT-BA. In particular, the rate of decrease in MPD was relatively high. The BPDs of the MPL-applied samples were slightly smaller than the others. Considering the principle of CFP, the BPD of the MPL-applied samples represents the diameter of the largest pores in the MPL. Although the pores in the MPL seem to be significantly smaller than those in the GDB (see SEM images in Fig. 2), the CFP results reveal that the diameter of the largest pores in the MPL were slightly smaller but comparable with

those in the GDB. In addition, the BPD of CT-VD-M was smaller than that of CT-AD-M. Measurements using different pieces of the same sample confirmed the reproducibility of this 
difference in BPD. There is a possibility that the PTFE distribution in the base material (i.e., GDB) affects the MPL morphology even when the ink slurry and coating procedure in the MPL application are the same for all MPL-coated samples.

Figure 4 shows a comparison of the water breakthrough pressure and calculated $\theta$ for five different samples. As mentioned above, two or three pieces of each GDL sample were used for the CFP and water breakthrough measurements. Error bars in Fig. 4 represent the divergence among those samples. Since the variation of measured data for water breakthrough pressure of CT-AD was very small, the error bar is invisible in this graph. The breakthrough pressure of CT-BA (4.90 kPa average) was in good agreement with literature data for the same sample (Toray 090) [34]. Comparison among the GDL samples without MPL (CT-BA, CT-AD, and CT-VD) reveals a higher water breakthrough pressure for the PTFE-treated samples (CT-AD and CT-VD) than for the untreated sample (CT-BA), which is a result that also agrees with that reported in the literature [34]. Here, the breakthrough pressure of CT-VD was higher than that of CT-AD even though the PTFE-loading amount was almost the same (Table 1). The $\theta$ calculated using $d_{\mathrm{p}}$ and breakthrough pressure, however, was similar for both samples (in the range from 140 to $150^{\circ}$ ), because the BPD in CT-VD was smaller than that in CT-AD. In addition, there was no significant difference in $\theta$ between CT-BA and either CT-AD or CT-VD. Considering the principle of $\theta$ definition, there is a difference in physical meaning between $\theta$ of sample with and without MPL. In the case of sample with MPL, because the thickness of MPL was relatively small $(\sim 40 \mu \mathrm{m})$ and the PTFE distribution must be uniform through the layer, $\theta$ could be exactly used as the indicator of hydrophobicity at the largest pore in MPL [18]. However, in the case of sample without MPL, the water path would have heterogeneous PTFE distribution in through-plane direction, and the average hydrophobicity at the largest pore was merely reflected in $\theta$. As described below (Sec. 3.4), the cell performance depended on the cathode GDL properties and significantly differed among these three samples (CT-BA, 
CT-AD, and CT-VD). Therefore, $\theta$ at the largest pore (i.e., BPD) is not the determining parameter for water discharge ability of GDB at any rate. On the other hand, the water breakthrough pressure of CT-AD-M and CT-VD-M was higher than that of CT-AD and CT-VD, respectively. Furthermore, a significant difference in the breakthrough pressure was observed between for CT-AD-M (5.96 kPa on average) and CT-CD-M (7.34 $\mathrm{kPa}$ on average), although their $\theta$ values were similar $\left(138.5^{\circ}\right.$ for CT-AD-M, $135.0^{\circ}$ for CT-CD-M in average). The similar $\theta$ for CT-AD-M and CT-VD-M indicates that the hydrophobicity of MPL pores also might be similar despite different BPD, because the PTFE content in MPL for both samples was the same. Interestingly, comparison among the five samples reveals that $\theta$ in MPL was not higher but somehow smaller than that in GDB, even though the MPL contained higher PTFE per weight compared with the GDB.

\subsection{Porosity and in-plane permeability}

The initial porosity of each sample measured with the decane wicking method is listed in Table 1. The initial porosity is similar for the samples of PTFE-treated GDB (CT-AD and CT-VD) at about 0.75 , and those of MPL-applied (CT-AD-M and CT-VD-M) at about 0.70 .

The measured in-plane permeability of each sample is also listed in Table 1 . The relative relation of in-plane permeability among CT-BA, CT-AD, and CT-VD is in good agreement with our previous study, that is, the in-plane permeability of CT-BA and CT-AD was similar, whereas that of CT-VD was significantly smaller than either CT-BA or CT-AD. This measured data suggests that the homogeneous distribution of PTFE achieved by the vacuum drying produces a porosity leveling, which means the porosity profile of PTFE-treated samples became more flat in the through-plane direction compared to that of the untreated samples. The smaller MPD of CT-VD compared with that of either CT-BA or CT-AD described above (Sec. 3.2) reinforces this hypothesis. In the case of MPL-applied samples (CT-AD-M and CT-VD-M), because the porosity of MPL was significantly 
lower than GDB, the observed data of in-plane permeability for CT-AD-M and CT-VD-M was significantly smaller than that for CT-AD and CT-VD, respectively, due to the lower permeability in the MPL portion. In addition, because the initial thickness of MPL-applied samples was larger than the samples without GDL, the compression ratio was high at the same spacer thickness. The difference in in-plane permeability between CT-AD-M and CT-VD-M can be explained by the same reason for that between CT-AD and CT-VD, as described above.

\subsection{Cell performance}

The $i-V$ characteristics were measured under the constant cell temperature of $70{ }^{\circ} \mathrm{C}$, while the humidification temperature $T_{\text {fuel }}$ of both gases $\left(\mathrm{H}_{2}\right.$ and air) was increased from 65 to $80^{\circ} \mathrm{C}$ in increments of $5^{\circ} \mathrm{C}$, and $\mathrm{RH}$ was thus changed from $80 \%$ to $152 \%$. Figure 5 shows the measured $i-V$ characteristics for three different cell set-ups using carbon-paper GDB without MPL as the cathode GDL, that is, CT-BA, CT-AD and CT-VD. Figures 5(a) and 5(b) show that the cells with PTFE-treated GDL (CT-AD and CT-VD) show better performance than that with untreated GDL (CT-BA) even when the RH was $80 \%$ and $100 \%$. In particular, the $i-V$ performance of CT-BA was slightly inferior to that of CT-AD and CT-VD even in low $i$ range $\left(<0.2 \mathrm{~A} \cdot \mathrm{cm}^{-2}\right)$. This indicates that the product water vapor was partially condensed into liquid under this $\mathrm{RH} .=80 \%$ condition and that the catalyst layer was somehow flooded by the product water due to weaker ability of water discharge through the GDL. Thus, even under dry condition, liquid-water discharge ability of GDL is critical for cell performance. When $\mathrm{RH}>124 \%$, it was impossible to measure meaningful $i-V$ characteristics for CT-BA due to severe flooding from low $i$. On the other hand, there is almost no difference between the performance of CT-AD and CT-VD until $i=2 \mathrm{~A} \cdot \mathrm{cm}^{-2}$ under this humidity condition $(\mathrm{RH}=80 \%)$. A noteworthy finding is a pronounced improvement in $i-V$ characteristics for CT-VD compared to CT-AD under wet conditions ( $\mathrm{RH} \geq 100 \%$ ) (Figs. $5 \mathrm{~b}, 5 \mathrm{c}$, and $5 \mathrm{~d})$. In addition, 
as $\mathrm{RH}$ was increased, the difference in limiting $i$ between CT-AD and CT-VD increased. This difference in limiting $i$ indicates a difference in mass transport limitation between these two GDLs. As listed in Table 1, the total amount of PTFE loading was almost the same for both the CT-AD and CT-VD samples. Because most of the product water must be in liquid state under these wet conditions, the difference in $i-V$ characteristics between these two samples must be attributed to the difference in liquid-water discharge ability due to the difference in PTFE distribution in the through-plane direction (as shown in Fig. 1). This difference in liquid-water discharge ability agrees with the literature data of ex-situ measurements for water transport rate through carbon-felt GDBs with homogeneous and heterogeneous distributions of PTFE reported by Quick et al. [11].

Figure 6 shows the comparisons of $i-V$ characteristics for two different cell set-ups using the MPL-applied carbon-paper GDB as the cathode GDL, that is, CT-AD-M and CT-VD-M. To compare the performance of all five cells, Figure 7 shows a plot of $i$ at the same $V$ (i.e., $0.6 \mathrm{~V}$ ) versus RH from $100 \%$ to $152 \%$. Comparison of CT-AD-M and CT-VD-M with CT-AD and CT-VD, respectively, shows that the application of MPL to CT-AD and CT-VD distinctly improved the performance under the wet condition $(\mathrm{RH} \geq 100 \%)$. This positive effect of MPL is similar to that reported by other studies [16-18]. A noteworthy result is the difference between CT-AD-M and CT-VD-M. We confirmed the reproducibility of this difference by repeated cell tests using different samples of the same type. Same as the reason for the difference between CT-AD and CT-VD, the difference in performance between CT-AD-M and CT-VD-M must be caused by the difference in mass transport limitation of GDLs. In terms of MPL properties, as described in Sec. 2.1, the composition of raw-slurry (carbon powder, PTFE, and water) and the application process (stirring, coating, drying, and sintering) were the same for both MPLs of the CT-AD-M and CT-VD-M samples. In addition, based on the SEM images (Fig. 2), the thickness of coated MPL seems to be similar for both samples, and according to the calculated $\theta$, the hydrophobicity was also similar for 
both samples, although the BPD of CT-VD-M was smaller than that of CT-AD-M (Table 1). These results indicate that the through-plane PTFE distribution in the carbon paper influenced the liquid-water discharge ability of the GDL even when the MPL was applied on the GDB.

Hinebaugh et al. [38] computed the dependence of the liquid water saturation profile on heterogeneous GDL porosity distribution. Their simulation results revealed that fluctuations (peaks and valleys) in the porosity distribution in the through-plane direction create highly saturated regions in the bulk of GDL. As listed in Table 1, the in-plane permeability of CT-VD and CT-VD-M was significantly lower than that of CT-AD and CT-AD-M, respectively, which are results identical with our previous study [15]. The homogeneous distribution of PTFE achieved by vacuum drying apparently promotes a uniform porosity distribution compared with the heterogeneous porosity distribution of either the untreated or PTFE air-dried sample. There is a possibility that the uniform porosity distribution in the through-plane direction formed in CT-VD and CT-VD-M improved the water discharge. However, because not enough porosity distribution data in the through-plane direction is available at present, this effect of porosity distribution on water discharge needs further verification.

Figure 8 shows ohmic resistance $\left(R_{\text {ohm }}\right)$ for five different cells measured by the FRA (at 10 $\mathrm{kHz}$ ) at the same $i$ range as the $i-V$ measurements shown in Figs. 5 and 6 . Error bars in this figure correspond to the change of $R_{\mathrm{ohm}}$ according to $i$ increase (from 0 to the limiting $i$ ). Because the limiting $i$ of CT-BA was extremely low $\left(<0.1 \mathrm{~A} \mathrm{~cm}^{-2}\right)$ when $\mathrm{RH} \geq 124 \%, R_{\mathrm{ohm}}$ of CT-BA is omitted from Figs. 8 (c) and 8 (d). Under the relative dry condition of RH $80 \%, R_{\text {ohm }}$ generally decreased with increasing $i$, thus the error bar is wide. Under dry condition $(\mathrm{RH}=80 \%), R_{\mathrm{ohm}}$ of CT-BA at OCV $\left(i=0 \mathrm{~A} \mathrm{~cm}^{-2}\right)$ was significantly larger than other cells even when RH was the same. The reason of this difference is not clear at present. The change in $R_{\text {ohm }}$ was large for CT-BA even under $\mathrm{RH}=100 \%$. Contrary to this, under wet conditions $(\mathrm{RH} \geq 100 \%), R_{\mathrm{ohm}}$ was relatively constant 
regardless of $i$, for all samples except CT-BA. In addition, the difference in $R_{\text {ohm }}$ between the other four cells (CT-AD, CT-VD, CT-AD-M, and CT-VD-M) was very small under wet conditions (RH $\geq$ $100 \%$ ). The maximum difference in ohmic overpotential ( $\left.i R_{\mathrm{ohm}}\right)$ at $1 \mathrm{~A} \cdot \mathrm{cm}^{-2}$ under RH of $100 \%$ was about $13 \mathrm{mV}$ for these four cells, and the difference was smaller under higher RH conditions (i.e., $\mathrm{RH}=124$ and $152 \%$ ). It was indicated that the membrane (and ionomer in CL) was fully hydrated under wet conditions ( $\mathrm{RH} \geq 100 \%)$ and the difference in contact resistance between CL and GDL was very small for these four cells.

Based on our results of the present study, the role of MPL for water transport is discussed as follows. The increase in water breakthrough pressure due to the MPL application described in Sec 3.2 was identical with that reported in previous results by Lu et al. [32] and Mortazavi and Tajiri [34]. If the MPL enhanced the back diffusion of water from the cathode to anode, there must be a correlation between the breakthrough pressure and $R_{\text {ohm. }}$ However, as shown in Figs. 4 and 8 , no relation between these two parameters was observed even under dry condition $(\mathrm{RH}=80 \%)$. On the other hand, the through-plane distribution of PTFE in the GDB affected the cell performance even when an MPL was applied. This indicates that the major part of liquid water formed at the interface of CL/MPL moves toward the channel through the MPL and GDB under wet conditions. The $\theta$ in MPL-applied samples was not higher but somehow smaller than that in GDBs, even though the MPL contained higher PTFE per weight than the GDB. Thus, it is difficult to explain the MPL role only from the view point of hydrophobicity. Consequently, it can be deduced that the hypothesis proposed by Gostick et al [21] and Lu et al. [32] is appropriate, that is, the MPL limits the number of water-entry locations into GDB and stabilizes the water path through the GDB, and thus, water saturation in GDL at breakthrough is reduced by the presence of MPL. During the liquid water transport through the GDB, the uniform distribution of PTFE must enhance the liquid-water discharge compared with the heterogeneous distribution of PTFE even when the MPL is present. Lee 
et al. [29] visualized liquid water distribution in GDL with MPL using synchrotron X-ray radiography, and their results indicated that the water content in the GDB region in GDL was higher than that in MPL. This observation reinforces our hypothesis that the water discharge ability of GDL depends not only on the properties of MPL but also on those of GDB.

\section{Conclusions}

This experimental study identified the effect of the through-plane PTFE distribution in GDB on cell performance. Our previous study reported that the PTFE distribution in GDB strongly depends on the drying condition; PTFE-drying under atmospheric pressure creates highly heterogeneous PTFE distributions in the through-plane direction, whereas PTFE-drying under vacuum pressure creates a relatively uniform PTFE distribution. In this current study, carbon paper samples with different PTFE distributions due to the difference in drying condition were prepared and used as the cathode GDL of PEMFCs. In addition to identifying the effect of the through-plane PTFE distribution, the effect of MPL application for these samples was also investigated.

An ex-situ approach was then applied for investigating the dynamic behavior of liquid water through GDLs with and without MPL. Both the PTFE treatment and MPL application increased the water breakthrough pressure of carbon-paper GDB, but had no significant effect on the contact angle calculated based on the pore diameter and breakthrough pressure. In particular, the contact angle of MPL-applied GDBs was rather smaller than that in GDB without MPL, even though the MPL contained higher PTFE per weight than the GDB.

The current density (i) - voltage $(V)$ characteristics of these samples measured under high RH conditions ( $80-152 \%)$ show that the cell performance was influenced by the through-plane distribution of PTFE in GDB with and without MPL, caused by the efficient transport of liquid water 
through the GDB due to the uniform distribution of PTFE. The ohmic resistance of the cell was immune to water breakthrough pressure, indicating that the back diffusion of water from cathode to anode was not a major mechanism of water transport in the cell, and that the liquid water transport through the GDB region plays an important role in water discharge from the GDL. Thus, to develop a robust GDL that could be applied for a wide range of humidity conditions, the properties of GDB (distribution of porosity and hydrophobicity) as well as that of MPL must be taken into account. 


\section{Acknowledgments}

The authors gratefully acknowledge the financial support from the Japan Science and Technology Agency (JST) through the Strategic Japanese-Chinese Joint Research Program for High-efficient Energy Utilization. The authors also thank Mr. Akira Takatsuki (AIST) for his SEM-EDS expertise. 


\section{Figure captions}

Figure 1. Schematic diagram of cross-section of GDL sample during (a) capillary flow porometry and (b) water injection measurement, when the largest pore diameter corresponds to "bubble point diameter (BPD)."

Figure 2. SEM images (upper) and corresponding EDS maps of fluorine (F) (bottom) of cross-sections of samples (a) CT-AD, (b) CT-VD, (c) CT-AD-M, and (d) CT-VD-M.

Figure 3. Through-plane PTFE distribution calculated from EDS map of F (Figs. 1 and 2) along respective thickness of GDL (z) from top (0) to bottom (1) for samples (a) CT-AD, (b) CT-VD, (c) CT-AD-M, and (d) CT-VD-M.

Figure 4. Measured water breakthrough pressure $\left(\Delta P_{\mathrm{WB}}\right)$ and calculated contact angle $\theta$ for each sample. Since the variation of measured data for water breakthrough pressure of CT-AD was very small, the error bar is invisible in this graph.

Figure 5. Current density (i) - voltage $(V)$ characteristics for three different cell set-ups for samples without MPL (CT-BA, CT-AD, and CT-VD) under various fuel humidification temperature $\left(T_{\text {fuel }}\right)$; (a) $65^{\circ} \mathrm{C} \quad(\mathrm{RH}=80 \%)$, (b) $70^{\circ} \mathrm{C}(\mathrm{RH}=100 \%)$, (c) $75^{\circ} \mathrm{C}(\mathrm{RH}=124 \%)$, and (d) $80^{\circ} \mathrm{C}(\mathrm{RH}=152 \%)$, when cell temperature $\left(T_{\text {cell }}\right)$ was $70^{\circ} \mathrm{C}$.

Figure 6. Current density $(i)$ - voltage $(V)$ characteristics for two cell set-ups for samples with MPL (CT-AD-M and CT-VD-M) under various fuel humidification temperature $\left(T_{\text {fuel }}\right)$; (a) $65^{\circ} \mathrm{C}$ 
( $\mathrm{RH}=80 \%)$, (b) $70^{\circ} \mathrm{C}(\mathrm{RH}=100 \%)$, (c) $75^{\circ} \mathrm{C}(\mathrm{RH}=124 \%)$, and (d) $80^{\circ} \mathrm{C}(\mathrm{RH}=152 \%)$, when cell temperature $\left(T_{\text {cell }}\right)$ was $70^{\circ} \mathrm{C}$.

Figure 7. Current density (i) plots at cell voltage $(V)$ of $0.6 \mathrm{~V}$ versus relative humidity $(\mathrm{RH})$ for five different cells.

Figure 8. Ohmic cell resistance $\left(R_{\mathrm{ohm}}\right)$ of each cell under various fuel humidification temperature ( $\left.T_{\text {fuel }}\right)$; (a) $65^{\circ} \mathrm{C}(\mathrm{RH}=80 \%)$, (b) $70^{\circ} \mathrm{C}(\mathrm{RH}=100 \%)$, (c) $75^{\circ} \mathrm{C}(\mathrm{RH}=124 \%)$, and (d) $80^{\circ} \mathrm{C}(\mathrm{RH}=152 \%)$, when cell temperature $\left(T_{\text {cell }}\right)$ was $70^{\circ} \mathrm{C}$. 


\section{References}

[1] L. Cinderella, A. M. Kannan, J. F. Lin, K. Saminathan, Y. Ho, C. W. Lin, J. Wertz, Gas diffusion layer for proton exchange membrane fuel cells - A review, J. Power Sources 194 (2009) $146-160$.

[2] A. Z. Weber, R. L. Borup, R. M. Darling, P. K. Das, T. J. Dursh, W. Gu, D. Harvey, A. Kusoglu, S. Lister, M. M. Mench, R. Mukundan, J. P. Owejan, J. G. Pharoah, M. Secanell, I. V. Zenyuk, A critical review of modeling transport phenomena in polymer-electrolyte fuel cells, J. Electrochem. Soc. 161 (2014) F1254-F1299.

[3] http://newsroom.toyota.co.jp/en/detail/4198334 (Toyota, page retrieved on November 2015).

[4] M. M. Mench, Q. L. Dong, C.Y. Wang, In situ water distribution measurements in a polymer electrolyte fuel cell, J. Power Sources 124 (2003) 90-98.

[5] X. Yang, N. Burke, C. Wang, K. Tajiri, K. Shinohara, Simultaneous measurements of species and current distributions in a PEFC under low humidity operation, J. Electrochem. Soc. 152 (2005) A759-A766.

[6] M. F. Mathias, J. Roth, J. Fleming, W. Lehnert, Diffusion media materials and characterization in: W. Vielstich, A. Lamm, H. A. Gasteiger (Eds.), Handbook of Fuel Cells, Vol. 3, John Wiley and Sons, West Sussex, 2003, Chap. 42.

[7] J. Moreira, A. L. Ocampo, P. J. Sebastian, M. A. Smit, M. D. Salazar, P. del Angel, J. A. Montoya, R. Pérez, L. Martínez, Influence of the hydrophobic material content in the gas diffusion electrodes on the performance of a PEM fuel cell, Int. J. Hydrog. Energy 28 (2003) $625-627$.

[8] C. Lim, C. Y. Wang, Effects of hydrophobic polymer content in GDL on power performance of a PEM fuel cell, Electrochim. Acta 49 (2004) 4149-4156. 
[9] G.G. Park, Y. J. Sohn, T. H. Yang, Y. G. Yoon, W. Y. Lee, C. S. Kim, Effects of PTFE contents in the gas diffusion media on the performance of PEMFC, J. Power Sources 131 (2004) 182-187.

[10] G. Lin, V. Nguyen, Effect of thickness and hydrophobic polymer content of the gas diffusion layer on electrode flooding level in a PEMFC, J. Electrochem. Soc. 152 (2005) A1942-A1948.

[11] C. Quick, D. Ritzinger, W. Lehnert, C. Hartnig, Characterization of water transport in gas diffusion media, J. Power Sources 190 (2009) 110-120.

[12] Z. Fishman, A. Bazylak, Heterogeneous through-plane porosity distributions for treated PEMFC GDLs, J. Electrochem. Soc. 158 (2011) B841-B845.

[13] A. Rofaiel, J. S. Ellis, P. R. Challa, A. Bazylak, Heterogeneous through-plane distributions of polytetrafluoroethylene in polymer electrolyte membrane fuel cells gas diffusion layers, J. Power Sources 201 (2012) 219-225.

[14] K. Kang, K. Oh, S. Park, A. Jo, H. Ju, Effect of spatial variation of gas diffusion layer wetting characteristics on through-plane water distribution in a polymer electrolyte fuel cell, J. Power Sources 212 (2012) 93-99.

[15] H. Ito, K. Abe, M. Ishida, A. Nakano, T. Maeda, T. Munakata, H. Nakajima, T. Kitahara, Effect of through-plane distribution of polytetrafluoroethylene in carbon paper on in-plane gas permeability, J. Power Sources 248 (2014) 822-830.

[16] Qi, A. Kaufman, Improvement of water management by a microporous sublayer for PEM fuel cells, J. Power Sources 109 (2002) 38-46.

[17] H. Li, Y. Tang, Z. Wang, Z. Shi, S. Wu, D. Song, J. Zhang, K. Fatih, J. Zhang, H. Wang, Z. Liu, R. Abouatallah, A. Mazza, A review of water flooding issues in the proton exchange membrane fuel cell J. Power Sources 178 (2008) 103-117.

[18] T. Kitahara, T. Konomi, H. Nakajima, Microporous layer coated gas diffusion layers for 
enhanced performance of polymer electrolyte fuel cells, J. Power Sources 195 (2010) $2202-2211$.

[19] A. Z. Weber, J. Newman, Effects of microporous layers in polymer electrolyte fuel cells, J. Electrochem. Soc. 151 (2005) A677-A688.

[20] X. Wang, H. Zhang, J. Zhang, H. Xu, X. Zhu, J. Chen, B. Yi, A bi-functional micro-porous layer with composite carbon black for PEM fuel cells, J. Power Sources 162 (2006) 474-479.

[21] J. T. Gostick, M.A. Ioannidis, M.W. Fowler, M.D. Pritzker, On the role of the microporous layer in PEMFC operation, Electrochem. Commun. 11 (2009) 576-579.

[22] L. R. Jordan, A. K. Shukla, T. Behrsing, N. R. Avery, B. C. Muddle, M. Forsyth, Effect of diffusion-layer on the performance of polymer electrolyte fuel cells operating at atmospheric pressure, J. Appl. Electrochem. 30 (2000) 641-646.

[23] X. L. Wang, H. M. Zhang, J. L. Zhang, H. F. Xu, Z. Q. Tian, J. Chen, H. X. Zhong, Y. M. Liang, B. L. Yi, Micro-porous layer with composite carbon black for PEM fuel cells, Electrochim. Acta, 51 (2006) 4909-4915.

[24] J. Yu, M. N. Islam, T. Matsuura, M. Tamano, Y. Hayashi, M. Hori, Improving the performance of a PEMFC with Ketjenblack WC-600JD carbon black as the material of the microporous layer, Electrochem. Solid-State Letters 8 (2005) A320-A323.

[25] S. Park, J. Lee, B. Popov, Effect of carbon loading in microporous layer on PEM fuel cell performance, J. Power Sources 163 (2006) 357-363.

[26] S. Park, J. Lee, B. Popov, Effect of PTFE content in microporous layer on water management in PEM fuel cells, J. Power Sources 163 (2008) 457-463.

[27] J. Chen, H. Xu, H. Zhang, B. Yi, Facilitating mass transport in gas diffusion layer of PEMFC by fabricating micro-porous layer with dry layer preparation, J. Power Sources 182 (2008) $531-539$ 
[28] R. P. Ramasamy, E. C. Kumbur, M. M. Mench, W. Liu, D. Moore, M. Murthy, Investigation of macro- and micro-porous layer interaction in polymer electrolyte fuel cells, Int. J. Hydrog. Energy 33 (2008) 3351-3367.

[29] J. Lee, R. Yip, P. Antonacci, N. Ge, T. Kotaka, Y. Tabuchi, A. Bazylak, Synchrotron investigation of microporous layer thickness on liquid water distribution in a PEM fuel cell, J. Electrochem. Soc. 162 (2015) F669-F676.

[30] J. Benziger, J. Nehlsen, D. Blackwell, T. Brennan, J. Itescu, Water flow in the gas diffusion layer of PEM fuel cells, J. Mem. Sci. 261 (2005) 98-106.

[31] J. T. Gostick, M.A. Ioannidis, M.W. Fowler, M.D. Pritzker, Direct measurement of the capillary pressure characteristics of water-air-gas diffusion layer system for PEM fuel cells, Electrochem. Commun. 10 (2008) 1520-1523.

[32] Z. Lu, M. M. Daino, C. Rath, S. G. Kandlikar, Water management studies in PEM fuel cells, part III: Dynamic breakthrough and intermittent drainage characteristics from GDLs with and without MPLs, Int. J. Hydrog. Energy 35 (2010) 4222-4233.

[33] D. Santamaria, P. K. Das, J. C. MacDonald, A. Z. Weber, Liquid-water interactions with gas-diffusion-layer surfaces, J. Electrochem. Soc. 161 (2014) F1184-F1193.

[34] M. Mortazavi, K. Tajiri, Liquid water breakthrough pressure through gas diffusion layer of proton exchange membrane fuel cell, Int. J. Hydrog. Energy 39 (2014) 9409-9419.

[35] T. Kitahara, H. Nakajima, K. Mori, Hydrophilic and hydrophobic double microporous layer coated gas diffusion layer for enhancing performance of polymer electrolyte fuel cells under no-humidification at the cathode, J. Power Sources 199 (2012) 29-36.

[36] Jena, K. Gupta, An innovative technique for pore structure analysis of fuel cell and battery components using flow porometry, J. Power Sources 96 (2001) 214-219.

[37] American Society for Testing, Material Committee, Standard Test Methods, for Pore Size 
Characteristics of Membrane Filters by Bubble Point and Mean Flow Pore Test, ASTM, F316-89, 1970, pp. 722-727.

[38] J. Hinebaugh, Z. Fishman, A. Bazylak, Unstructured pore network modeling with heterogeneous PEMFC GDL porosity distributions, J. Electrochem. Soc. 157 (2010) B1651-B1657. 
Table 1

Table 1. GDL properties at cathode for PEFC set-ups. ${ }^{\text {a }}$

\begin{tabular}{|c|c|c|c|c|c|c|c|c|c|c|c|}
\hline \multirow{2}{*}{ Cell notation } & \multirow{2}{*}{$\begin{array}{c}\text { GDB } \\
\text { (cathode) } \\
\text { substrate }\end{array}$} & \multirow{2}{*}{ MPL } & \multirow{2}{*}{$\begin{array}{c}\text { PTFE } \\
\text { treatment for } \\
\text { GDB }\end{array}$} & \multicolumn{2}{|c|}{ Thickness } & \multicolumn{2}{|c|}{ PTFE loading } & \multirow{2}{*}{$\begin{array}{c}\text { Porosity } \\
\text { GDB+MPL } \\
\text { [-] }\end{array}$} & \multirow{2}{*}{$\begin{array}{c}\text { Bubble point } \\
\text { diameter } \\
\text { GDB+MPL } \\
{[\mu \mathrm{m}]}\end{array}$} & \multirow{2}{*}{$\begin{array}{c}\text { Mean } \\
\text { pore } \\
\text { diameter } \\
\text { GDB } \\
{[\mu \mathrm{m}]}\end{array}$} & \multirow{2}{*}{$\begin{array}{c}\text { In-plane } \\
\text { permeability } \\
\text { c } \\
\text { GDB+MPL } \\
{\left[\mathrm{m}^{2}\right]}\end{array}$} \\
\hline & & & & $\begin{array}{l}\text { GDB } \\
{[\mu \mathrm{m}]}\end{array}$ & $\begin{array}{c}\text { GDB+MPL } \\
{[\mu \mathrm{m}]}\end{array}$ & $\begin{array}{c}\text { GDB } \\
\text { [wt. \%] }\end{array}$ & $\begin{array}{c}\mathrm{GDB}+\mathrm{MPL}^{\mathrm{b}} \\
\text { [wt. \%] }\end{array}$ & & & & \\
\hline CT-BA & Toray 090 & - & - & 285 & & - & & 0.809 & 33.2 & 17.6 & $5.33 \times 10^{-12}$ \\
\hline CT-AD & Toray 090 & - & Air-dry & 295 & & 4.88 & & 0.753 & 33.9 & 16.3 & $5.20 \times 10^{-12}$ \\
\hline CT-VD & Toray 090 & - & Vacuum-dry & 295 & & 5.15 & & 0.751 & 28.7 & 11.9 & $3.49 \times 10^{-12}$ \\
\hline CT-AD-M & Toray 090 & Applied & Air-dry & 282 & 320 & 6.47 & 8.37 & 0.692 & 26.1 & & $3.23 \times 10^{-12}$ \\
\hline CT-VD-M & Toray 090 & Applied & Vacuum-dry & 285 & 320 & 4.91 & 7.90 & 0.716 & 20.0 & & $1.51 \times 10^{-12}$ \\
\hline
\end{tabular}

a: Carbon paper GDL (without PTFE treatment and MPL) was used for the anode GDL.

b: PTFE content in MPL was 27 wt. \%.

c: Measured value with the spacer thickness of $200 \mu \mathrm{m}$. 


\section{Figure 1}

(a)

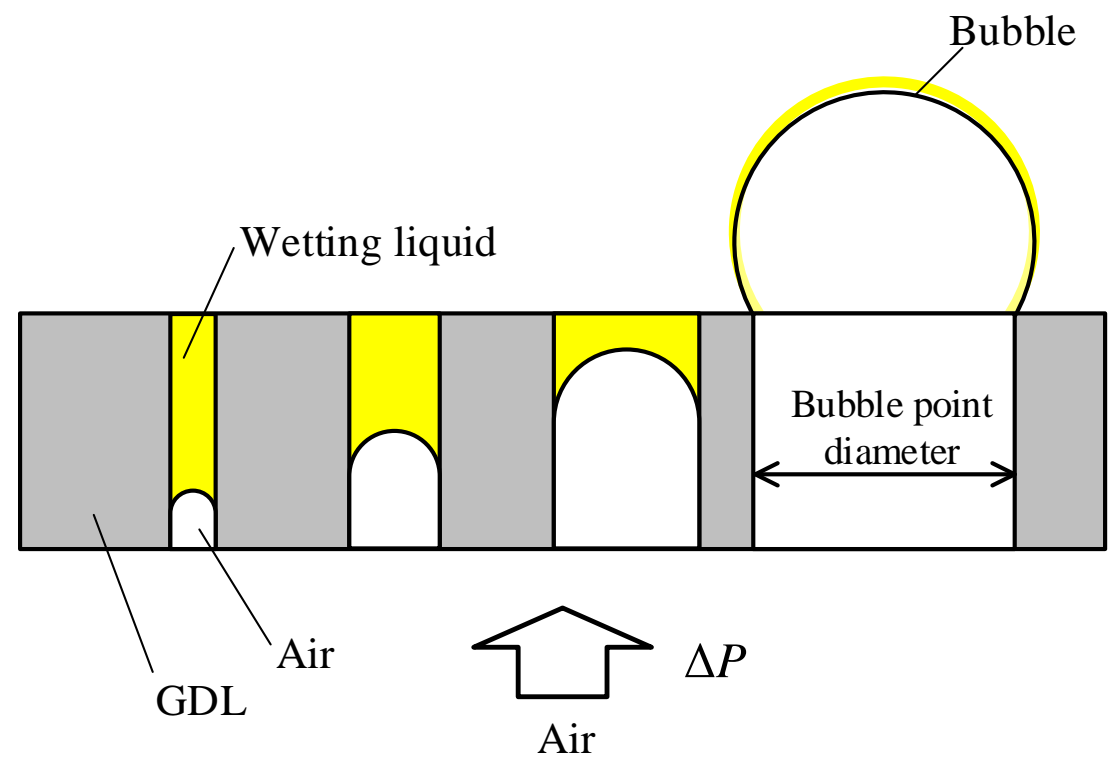

(b)

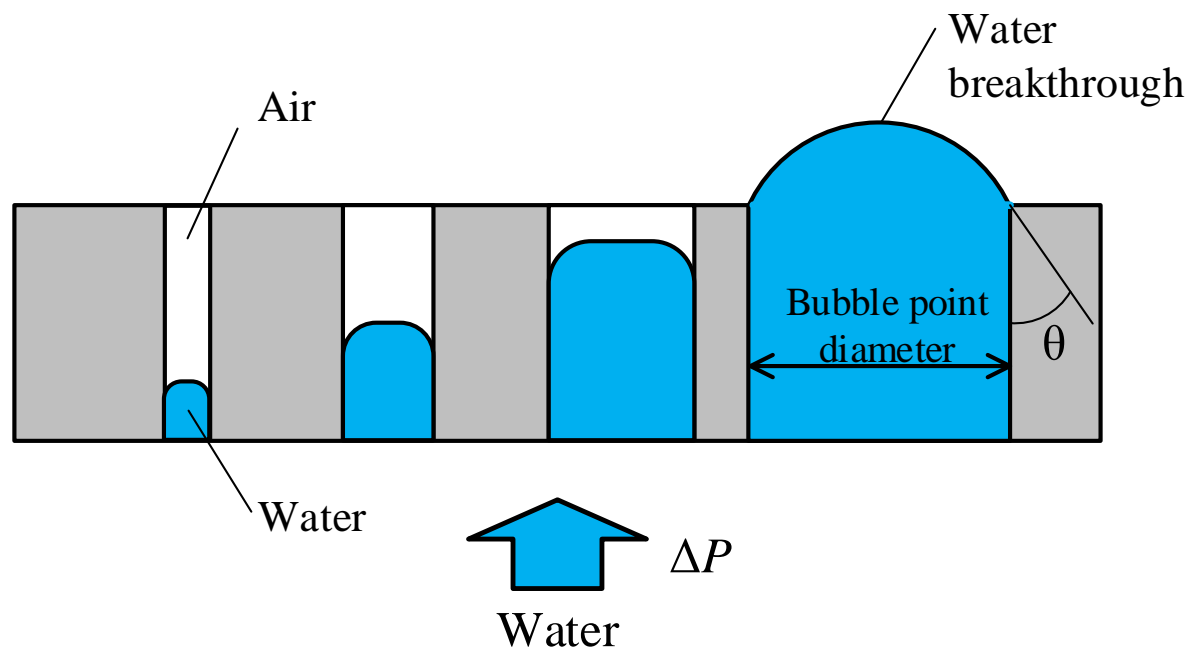

Figure 1. Schematic diagram of cross-section of GDL sample during (a) capillary flow porometry and (b) water injection measurement, when the largest pore diameter corresponds to "bubble point diameter (BPD)." 
Figure 2

(a) CT-AD

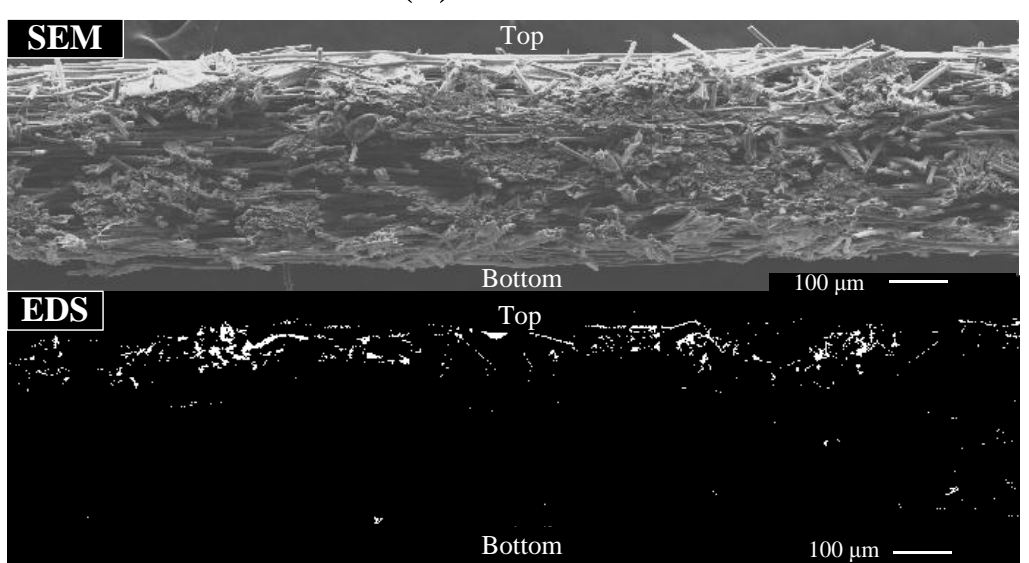

(c) CT-AD-M

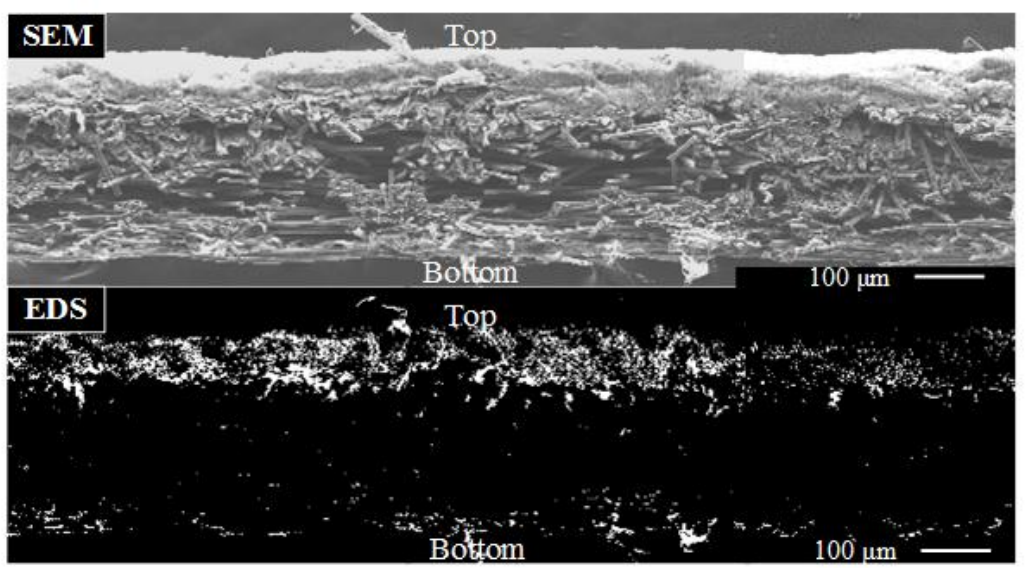

Figure 2. SEM images (upper) and corresponding EDS maps of fluorine (F) (bottom) of cross-sections of samples (a) CT-AD, (b) CT-VD, (c) CT-AD-M, and (d) CT-VD-M.

\section{(b) CT-VD}

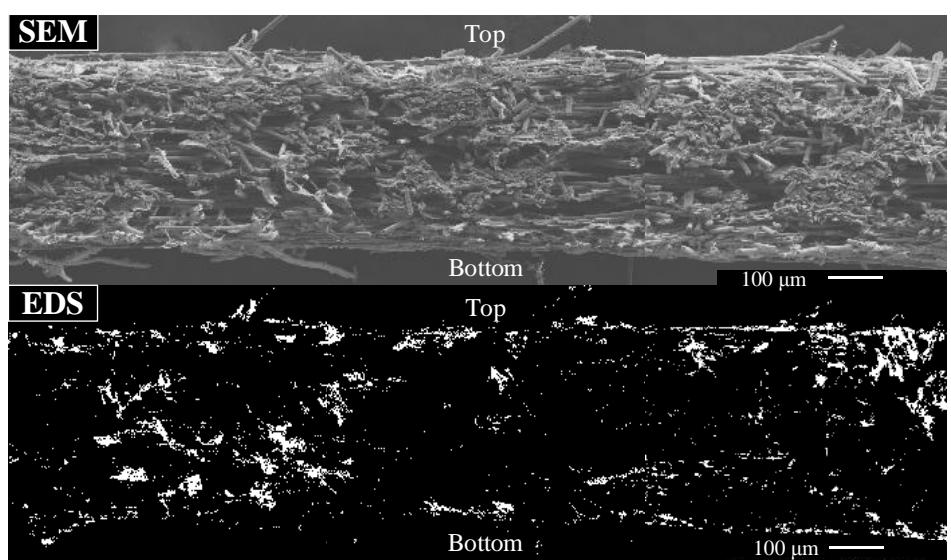

(d) CT-VD-M

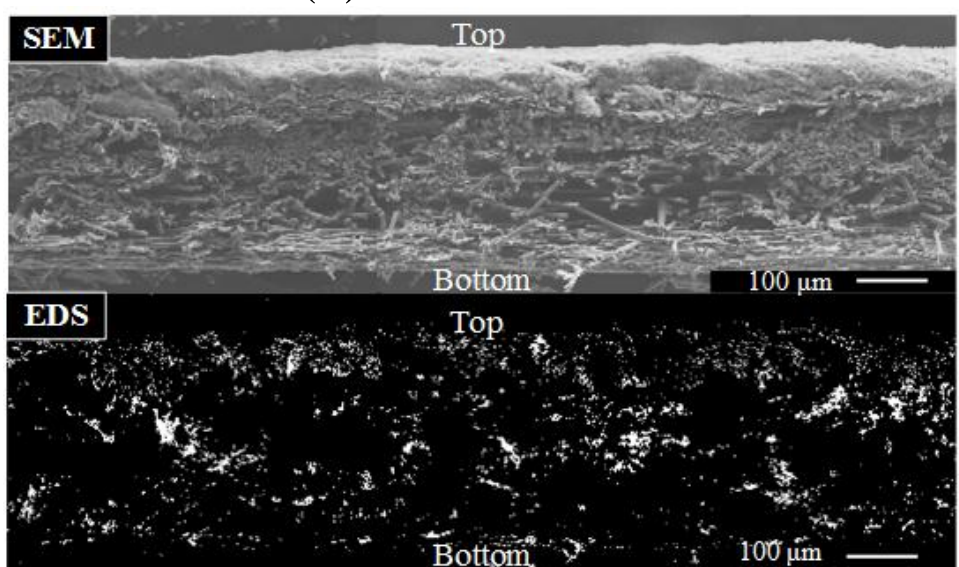


Figure 3
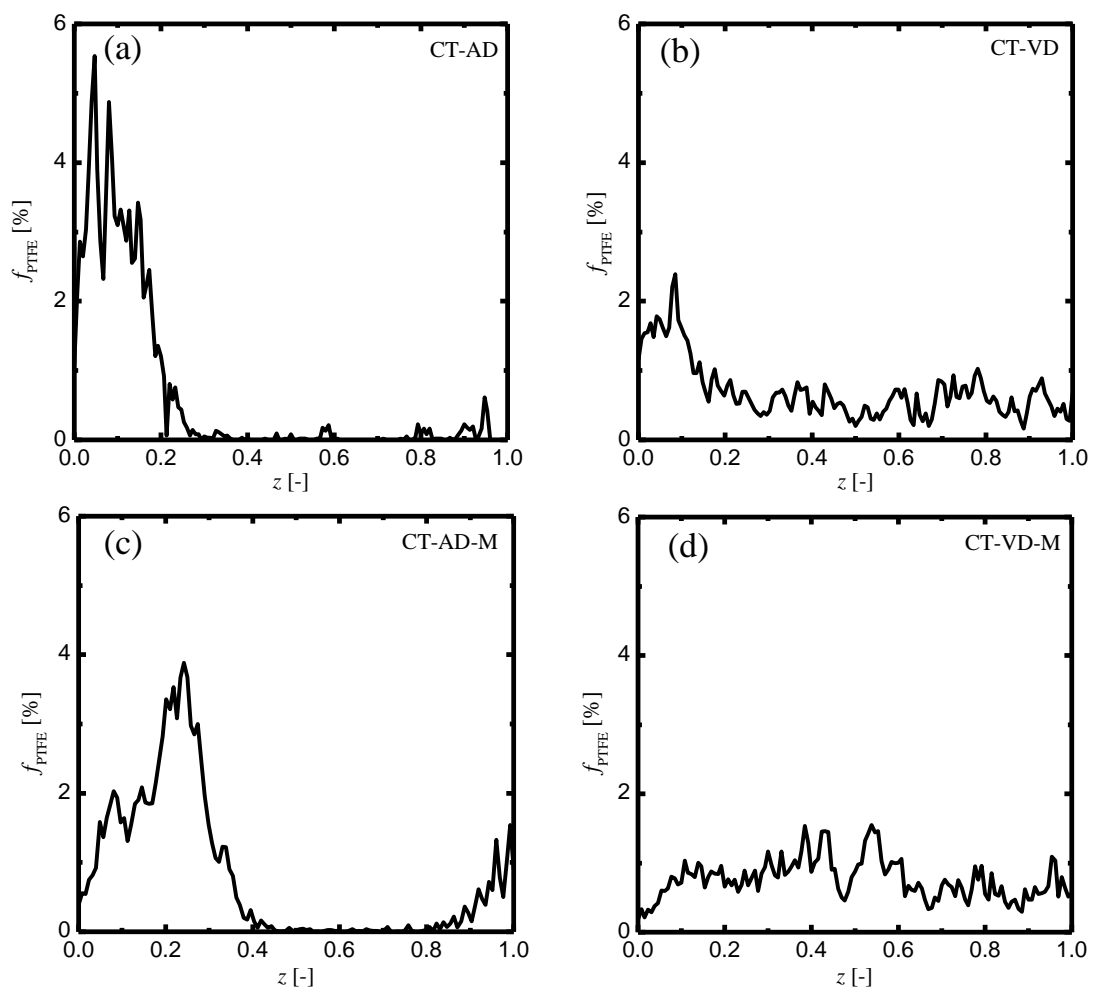

Figure 3. Through-plane PTFE distribution calculated from EDS map of F (Figs. 1 and 2) along respective thickness of GDL (z) from top (0) to bottom (1) for samples (a) CT-AD, (b) CT-VD, (c) CT-AD-M, and (d) CT-VD-M. 
Figure 4

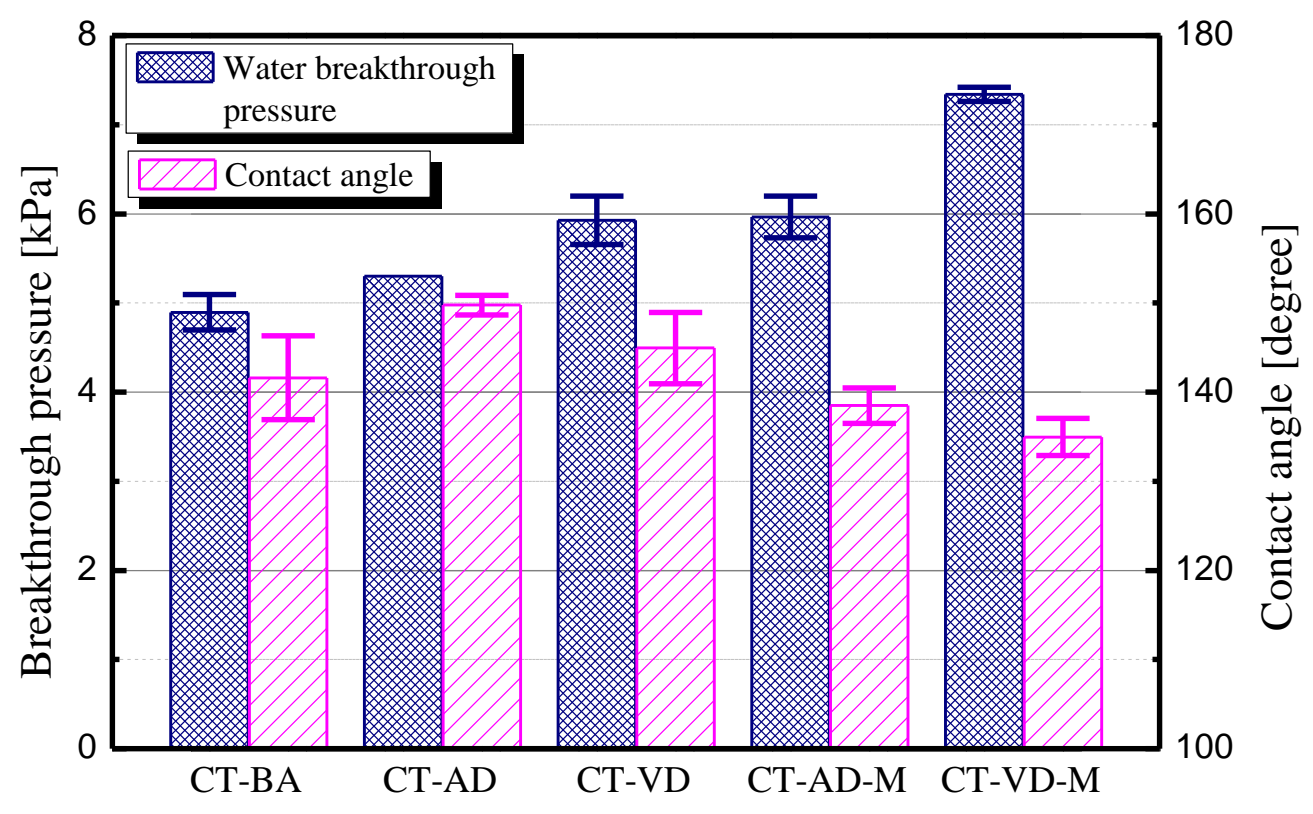

Figure 4. Measured water breakthrough pressure $\left(\Delta P_{\mathrm{WB}}\right)$ and calculated contact angle $\theta$ for each sample. Since the variation of measured data for water breakthrough pressure of CT-AD was very small, the error bar is invisible in this graph. 


\section{Figure 5}
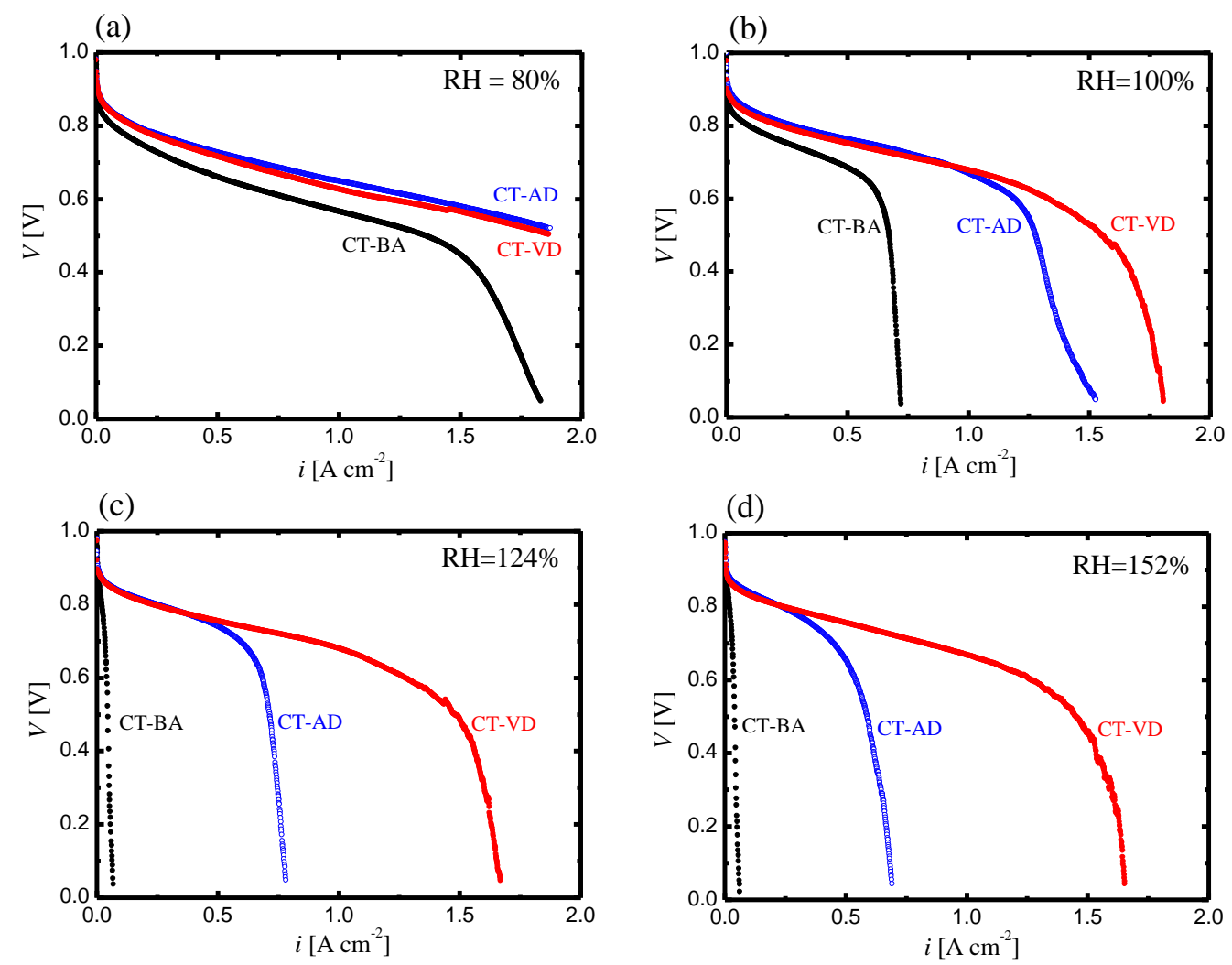

Figure 5. Current density $(i)$ - voltage $(V)$ characteristics for three different cell set-ups for samples without MPL (CT-BA, CT-AD, and CT-VD) under various fuel humidification temperature ( $\left.T_{\text {fuel }}\right)$; (a) $65^{\circ} \mathrm{C} \quad(\mathrm{RH}=80 \%),\left(\right.$ b) $70^{\circ} \mathrm{C}(\mathrm{RH}=100 \%)$, (c) $75^{\circ} \mathrm{C}(\mathrm{RH}=124 \%)$, and (d) $80^{\circ} \mathrm{C}(\mathrm{RH}=152 \%)$, when cell temperature $\left(T_{\text {cell }}\right)$ was $70^{\circ} \mathrm{C}$. 


\section{Figure 6}
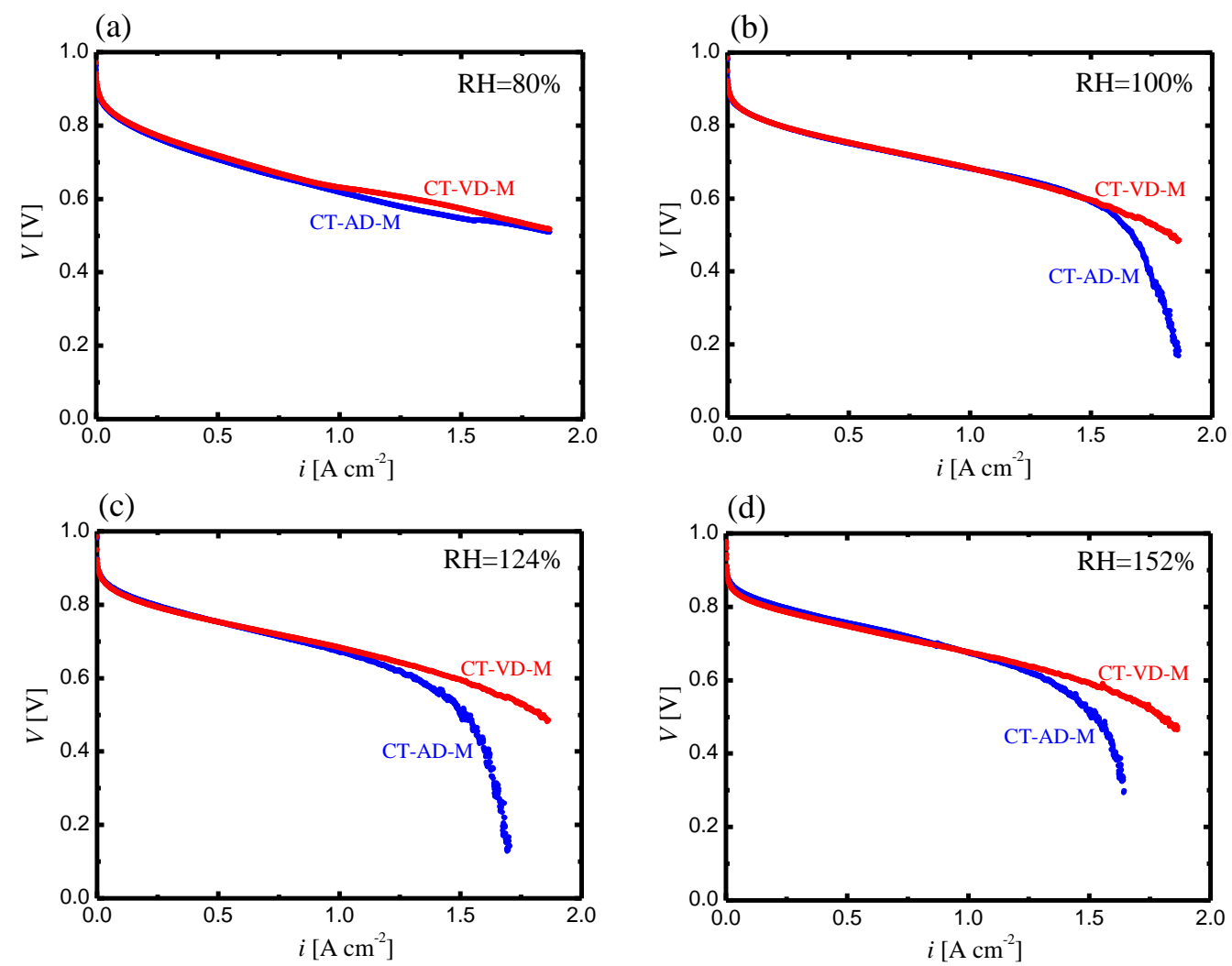

Figure 6. Current density $(i)$ - voltage $(V)$ characteristics for two cell set-ups for samples with MPL (CT-AD-M and CT-VD-M) under various fuel humidification temperature ( $\left.T_{\text {fuel }}\right)$; (a) $65^{\circ} \mathrm{C}$ (RH=80\%), (b) $70^{\circ} \mathrm{C}(\mathrm{RH}=100 \%),\left(\right.$ c) $75^{\circ} \mathrm{C}(\mathrm{RH}=124 \%)$, and (d) $80^{\circ} \mathrm{C}(\mathrm{RH}=152 \%)$, when cell temperature $\left(T_{\text {cell }}\right)$ was $70^{\circ} \mathrm{C}$. 
Figure 7

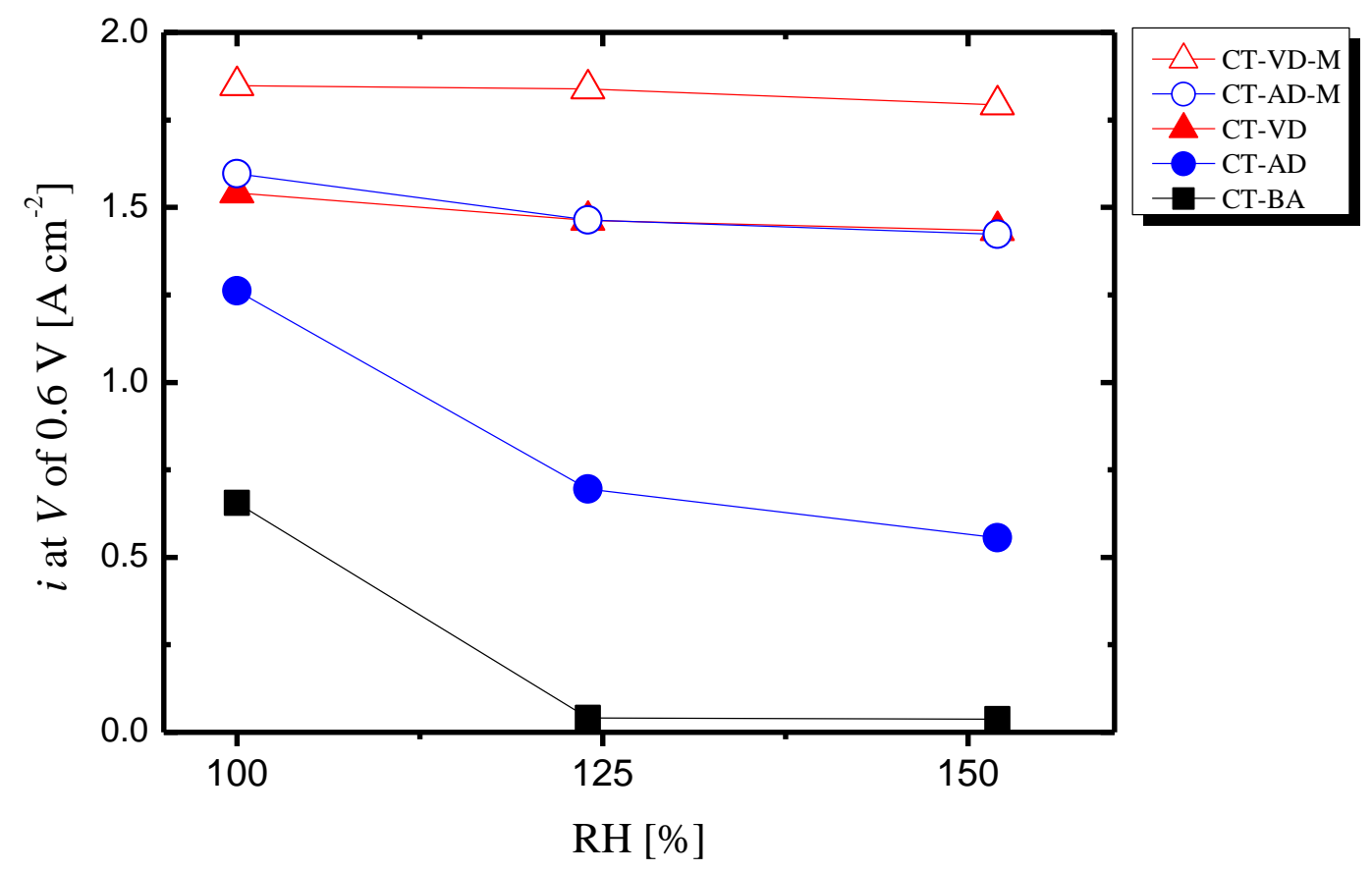

Figure 7. Current density $(i)$ plots at cell voltage $(V)$ of $0.6 \mathrm{~V}$ versus relative humidity $(\mathrm{RH})$ for five different cells. 


\section{Figure 8}
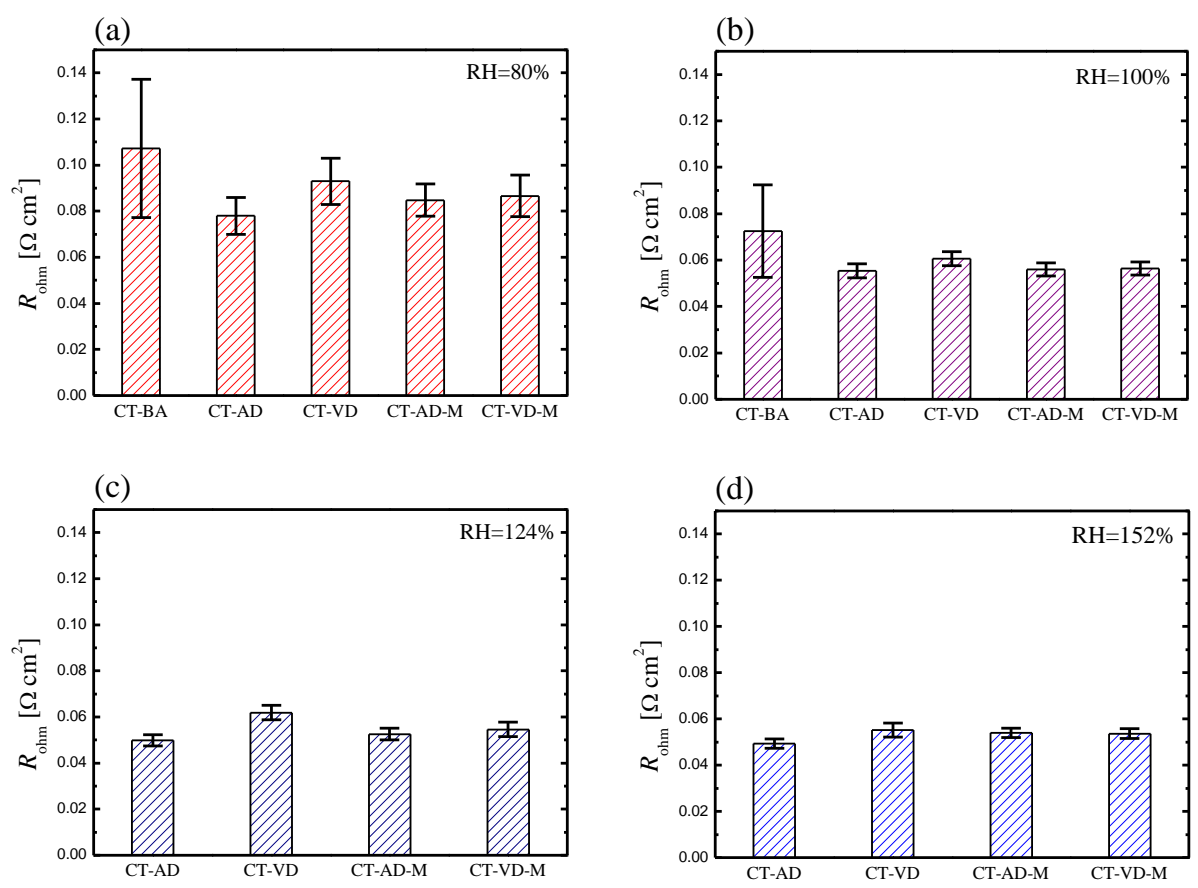

Figure 8. Ohmic cell resistance $\left(R_{\mathrm{ohm}}\right)$ of each cell under various fuel humidification temperature ( $\left.T_{\text {fuel }}\right)$; (a) $65^{\circ} \mathrm{C}(\mathrm{RH}=80 \%)$, (b) $70^{\circ} \mathrm{C}(\mathrm{RH}=100 \%)$, (c) $75^{\circ} \mathrm{C}(\mathrm{RH}=124 \%)$, and (d) $80^{\circ} \mathrm{C}(\mathrm{RH}=152 \%)$, when cell temperature $\left(T_{\text {cell }}\right)$ was $70^{\circ} \mathrm{C}$. 